\title{
CONVERSATIONS ABOUT ASSESSMENT AND LEARNING
}

\author{
EDUCATIONAL DEVELOPMENT SCHOLARSHIP \\ THAT MAKES A DIFFERENCE
}

Sue Fostaty Young, Susan Wilcox, Queen's University

To facilitate deeper understanding of teachers' assessment practices, we undertook an educational development inquiry with college and university faculty. Our conversations with instructors about their assessment practices highlighted the complex relationship between teachers' beliefs about teaching, their institutional contexts, and their experiences of teaching. The project gave us valuable opportunities to examine our interactions with faculty and enabled us to identify approaches to educational development that help postsecondary faculty understand and improve their practice.

Assessment can be a very positive force for student learning. As teachers create tasks through which to gather and interpret information about student learning, they shape students' approaches to course material (Biggs, 2003). The project we describe in this chapter had two broad purposes: first, to explore the connection between postsecondary teachers' assessment practices and their intentions for student learning by examining influences on the choices teachers make when they conduct assessment; and second, to learn about assessment in a way that offered immediate benefits to the teachers we were learning from and helped us acquire more effective strategies for educational development concerning assessment practices. Our ultimate goal is to promote development of assessment beliefs and practices that will best support student learning in higher education.

Underlying this initiative is our vision of educational development as scholarship uniting research and practice. We are particularly interested in promoting collaborative self-study with teachers as a means of 
understanding and improving teaching and learning. Self-study is a mode of scholarly inquiry in which teachers examine their beliefs and actions for the purpose of improving their practice (Louie, Drevdahl, Purdy, \& Stackman, 2003; Whitehead, 1993). For example, Richards and BarksdaleLadd (1997) used cases describing educational problems to unearth subconsciously held professional beliefs that influenced teachers' decisionmaking processes. Self-study inquiry can promote transformational educational development (Wilcox, Watson, \& Paterson, 2004) and as such is entirely suited to the purposes of this particular project. In practical terms, this meant we were committed to reflecting on our own educational development practices while at the same time helping faculty participants take a self-reflective approach to their teaching.

\section{Background}

Conceptions of teaching are presented in the literature as idiosyncratic, largely unarticulated composites of assumptions, knowledge, and beliefs about learning, and how to facilitate it, that teachers amass through past and ongoing experience (for example, Biggs, 1999; Entwistle, Skinner, Entwistle, \& Orr, 2000). Teachers' implicit theories have a stronger influence on their practice than their cognitive reasoning does (Kember, 1997; Pratt, 1992; Samuelowicz \& Bain, 1992, 2002). Kane, Sandretto, and Heath (2002) conducted a comprehensive critical analysis of existing studies on academics' teaching beliefs and practices and concluded that there is a real need for research interventions "that enable university academics to make explicit their own theories-in-use and to interrogate these in light of espoused theories and intentions" (p. 200). In educational development terms, teachers' practice is unlikely to develop unless their conceptions of teaching also develop (Akerlind, 2004; Ho, Watkins, \& Kelly, 2001).

Therefore, we need to engage faculty members in meaningful interactions that help them develop and then act on sophisticated conceptions of teaching (Wilcox, 2000) with the ultimate aim of supporting and eliciting the type of learning outcomes and ends expected through higher education. We anticipated that guiding teachers through an exploration of beliefs and practices might facilitate their understanding of the motivations for their actions. We accept Schön's assertion (1987) that when teachers reflect on their actions, they may be able to uncover previously unarticulated assumptions that informed those actions. When we can make explicit the assumptions that shape conceptions of teaching, those assumptions become more susceptible to change (Mezirow, 2000).

Pratt (1992) identified assessment as the aspect of teaching that, more than any other, reveals an individual's dominant beliefs about teaching 
and learning. Assessment is also recognized to be the single most important factor influencing students' approaches to learning (Biggs, 2003; Boud, 1990; Ramsden, 1992). Students interpret a teacher's system of values through what and how she or he chooses to assess (Boud, 1990; Gass, 2004), thus the critical need for assessment practices to be aligned with intentions for learning (Biggs, 2003; Gibbs \& Simpson, n.d.). Brookfield (1995) urged teachers to "take a long, hard look at your evaluative criteria and indicators" (p. 112). For all these reasons, we were keen to explore the impact of teachers' conceptions of teaching and learning on their assessment practices.

Wilson (1990) contended that any effort to understand assessment practices that does not also attempt to locate those practices in an educational context is "doomed to failure" (p. 227); because teachers' assessment beliefs and practices may be constrained by institutional expectations and conditions. Class size and student ability are two conditions commonly assumed to affect assessment practices, but other factors come to mind as well. For example, in some institutions course learning outcomes are fixed, but the choices of text(s), delivery method(s), learning activities, and method(s) of assessment are up to the teacher. In this case, teachers are expected to make instructional decisions that will support the stated learning outcomes, but it is uncertain how and whether they make this connection. In other settings, most aspects of course design and implementation are up to the individual instructor. In theory, teachers in such settings are free to conduct assessment in ways they feel will best document achievement of intended student learning outcomes, but is this the case? We felt compelled to explore aspects of institutional context as an area of influence regarding teachers' assessment choices.

Recognizing the impact of assessment on student learning and appreciating the intimate relationship among teachers' beliefs about teaching, their institutional contexts, and their assessment choices, we concluded that a collaborative self-study of teachers' assessment beliefs and practices would be an especially fruitful approach to educational development scholarship.

\section{Approach}

We invited four teachers to participate in an examination of assessment beliefs and practices with the two of us. We chose four because it allowed us to delve intensely into conversation with them about particular practices. Having two educational developers involved in this small project enabled productive conversation with a colleague about the process and findings. 
We were interested in how these teachers' conceptions of teaching and learning related to their assessment practices and how institutional contexts influenced their conceptions of teaching and learning and shaped their assessment practices. We hoped this critical inquiry into practice would be of immediate benefit to the teachers involved and would help us devise ways of working effectively with teachers to help them reflect on their assessment beliefs and practices and make wise assessment choices.

\section{Participants}

The authors and project leaders are experienced educational developers with a disciplinary background in adult and higher education. We are skilled consultants regarding postsecondary assessment practices but have had few opportunities to reflect on assessment issues in collaboration with teachers.

Two college and two university faculty members accepted our invitation to explore assessment with us. We knew the university teachers at our own institution to be thoughtful and successful teachers who took their teaching seriously; the college teachers were recommended to us for similar reasons by the academic vice president at a neighboring institution. (The province of Ontario's colleges of applied arts and technology focus on career preparation through certificate, diploma, and apprenticeship programs, although some programs lead to a degree.) Participating faculty (three women, one man) came from disparate disciplines: one college teacher taught public relations, consumer behavior, and marketing, and the second taught accounting. One university professor taught politics while the second taught microbiology. All were experienced instructors with fifteen to thirty years in the classroom. As with most postsecondary teachers, they did not have much formal preparation for teaching. Although one college instructor had completed a Teacher of Adults certificate, the others had learned through occasional participation in teaching development workshops, interactions with a senior mentor, consultation with educational development specialists, or informal discussion with colleagues. Each participant completed a written questionnaire and met twice with one of us for conversations about assessment practices.

\section{Questionnaire}

We designed and administered a questionnaire based on items available on standard teaching questionnaires. Included, for example, were items from the Assessment Experience Questionnaire (Gibbs \& Simpson, 2003) and from our university's new faculty questionnaire, which asks respondents 
whether particular statements about teaching reflect their own views (based on Kember \& Kwan, 2000). In their responses, participants identified relevant material to discuss during our conversations.

\section{Conversations}

We reviewed the completed questionnaires and identified some initial topics for the one-on-one conversations. Our conversations always began with participants' comments on or questions about the project. We then asked if they wanted to address any one issue first. Together, we then went through the questionnaire to areas that either we had identified for elaboration or the instructor wanted to talk about. We took notes during the conversation. At the close of the first meeting, we asked participants to bring an artifact from their teaching and assessment practice to our second meeting. We left selection of items up to the participants, hoping they would choose something significant and evocative to facilitate a rich discussion.

Luce-Kapler (2006) proposed the side-shadow interview as a useful technique for exploring the nature of a process such as writing or teaching. The technique helps the writer or teacher engaged in decision making see "the path of decision nestled among alternative pathways." During side-shadow interviews, an interested "other" reviews an individual's "text" with him or her using both prepared questions and conversational discovery. The interviewer asks the interviewee to talk about the choices made in the text. We experimented with this technique during our second meeting with teacher participants. The artifact supplied by each teacher served as the "text" under discussion. We audiotaped and later transcribed these conversations.

\section{Postintervention Analysis}

After our meetings with the teachers, we reviewed the records of our conversations and their responses to the initial questionnaire. None of the participants accepted our offer of a copy of the transcript of our tape-recorded conversations for their review. But to ensure accuracy, along with a letter of thanks we sent a synopsis of each conversation to the participants and asked for their feedback. Every participant verified that we had accurately captured what was said. In reviewing the records, our goal was to identify (1) themes and insights about influences on these teachers' assessment practices and (2) how our future interventions with teachers might improve postsecondary assessment practices. Faculty participants did not contribute 
directly to this aspect of the project. We did share a final copy of this manuscript with them and once again asked them to advise us if we had misrepresented them, or the process, in any way. All were satisfied with project outcomes as we had described them.

\section{Outcomes}

Here we focus on communicating the value of this "inquiry" approach to educational development by describing some of what we learned while working with the participating instructors. We do not mean to suggest that our findings about these teachers' particular approaches to assessment are especially significant. We do wish to convey something of the flavor of our conversations so that others who wish to engage in this form of developmental scholarship will know what to expect from the process.

\section{Questionnaires}

Responses to the initial questionnaires furnished us with some helpful information about the participants. For example, we learned that one teacher with thirty years' experience was not very confident in his skills as a teacher (rating himself as 3 on a scale of 1 to 10 , where 10 is very confident), while the other three teachers were very confident ( 9 on the scale) in their teaching skills. Interestingly, all rated the caliber of their students quite highly, ranging from 7 to 10 on a scale of 1 to 10 where 10 is excellent. We learned that these teachers described themselves as more focused on "helping students learn" than on "measuring students' learning." We were encouraged to find that all the participants were well able to describe both their strengths and their weaknesses and to describe how their students probably viewed them. They reported that they used or had used quite a range of assessment strategies, including essay assignments, open-book essay exams, objective tests/exams/quizzes, take-home exams, oral presentations, group project reports, class attendance and participation, and lab reports. Their assessment challenges included "giving useful feedback," "assigning fair grades," "correcting students' style," "avoiding favoritism or bias," "finding enough time for grading," and "giving marks to a poorly presented paper"-in other words, nothing unusual.

\section{Conversations}

Our subsequent conversations helped us understand how individual teachers think about assessment in specific contexts. One participant simply described his methods of assessment-the oral presentations, participa- 
tion, journals, and exams he used. The other three readily detailed the assessment strategies they had put in place in one or more of their courses. Their strategies incorporated such things as performance criteria, communication of requirements to students, the mixture of assessment methods, grading policies, and mechanisms for providing feedback. These participants explained how their assessment approaches fitted the learning outcomes they valued. For example, having maintained strong ties to their respective work fields, both college instructors designed assessment tasks that reflected the skill set demanded by prospective employers. Valuing critical thinking and analytic research skills, the politics teacher developed assignments that targeted those skills. The fourth participant also connected his rather rudimentary notion of assessment with valued learning outcomes, indicating that his students gained a lot of skills doing the tasks he assigned.

All four faculty were intentional about their assessment strategies, even if their approach was not particularly sophisticated. Their decisions were clearly based on their understanding of what students needed to learn in their course. The two university faculty members seemed to rely heavily on personal beliefs about the content and learning processes that were most desirable for their students to demonstrate, while the college faculty members used graduate employment criteria to guide the content and format of their assessment tools.

When discussing assessment challenges, the college instructors seemed particularly concerned that their grading practices be manageable, reasonable, and fair. Grades should reflect the students' level of competence in a particular field, as measured through tests and assignments. At the same time, these teachers indicated that the students should be expected to demonstrate competence only in areas that had been taught, and that they must know up-front what is expected of them. These faculty also expressed interest in finding ways to assess that were feasible given their workload.

The two university instructors were more interested in discussing grading practices that encouraged student engagement and promoted learning. They seemed to assume that most students would meet the basic course requirements and attain a good grade. Their challenge was finding assessment strategies to motivate students to do the kind of work that resulted in real learning.

In discussing the reasons behind their assessment approach, all the participants talked about the quality of their students' learning and identified ways in which their assessment strategies influenced learning. Some participants recounted how they modified their approach in order 
to improve learning by introducing rubrics and authentic assessment tasks to replace tests. Still, their level of awareness of the practices was not especially high. For example, one teacher explained that his assessment approach differed between two of his courses because one course was more student-oriented while the other was more teacher-focused. But he could not articulate why he approached the two courses so differently.

All four participants said they considered class size in selecting assessment methods, but they did not necessarily abandon worthwhile assessment strategies simply because class size made the strategies harder to implement. Rather, they were more likely to include a complementary assessment strategy (for example, rubrics, group work, self- or peerassessment) that enabled them to assess a larger class effectively.

Participants were invited to talk about how institutional grading policies influenced their assessment practices. One college teacher insisted that grading policies had no impact at all. Yet she interpreted the college's policy that "student work must be consistently outstanding to earn an A" to mean that only three or four students in each of her sections could achieve an $A$, and she graded in a way that reflected this thinking. The other college instructor commented disparagingly on a recent change to an institutional grading policy: a pass is now 50 percent where it used to be 60 percent. In her view, this change lowered students' motivation because "many just want to pass." However, she stated that course learning outcomes and her knowledge of the job requirements in the field most influenced her approach to assessment, not the college's policies.

One of the university instructors did not know whether his institution had any official grading policies. He described a departmental culture in which faculty did not discuss teaching, so he did not know how his colleagues approached assessment. He did know that his graduate students had to maintain an A average to receive funding, and so he graded to avoid putting their funding at risk. Rather than addressing institutional grading policies, the other university instructor chose to comment on the reaction of her departmental colleagues to the grades she gave. Her colleagues complained that her grades were too high, while she contended that the grades accurately reflect the quality of her students' learning. In her department, the official grading policy appeared to be irrelevant, and grading practices were considered a professional prerogative that nonetheless colleagues could challenge. For both these university faculty, the informal assessment and evaluation culture of their respective departments significantly influenced their assessment practices and their reflection on their assessment practices. 


\section{Exhibit 9.1. Factors Affecting Assessment Choices}

Educator identity (authenticity)

- Who am I and what do I value?

Educator role (influence)

- How can I best help students learn?

- What part do I play in their learning?

Educator limits (finding balance)

- How much am I prepared to do?

Prior assessment experiences of educator (knowledge)

- What have I "learned" about assessment through experience?

Assessment skills of educator (ability)

- What do I know how to do?

Ecology of assessment (context)

- How does my approach to assessment fit within the assessment climate or culture in my unit or institution?

- What is the relationship between my own values and practices and the values and practices of my colleagues?

- Is it necessary to achieve integration?

Educator's assumption about students (expectations)

- Who are my students?

Intended learning outcomes (broad and specific goals)

- What do my students need to learn?

When we met a second time with the participants, we were able to delve further into the various factors that influenced these instructors' assessment practices. We were able to identify eight interrelated factors shaping their decisions about how best to conduct assessment (see Exhibit 9.1).

\section{Discussion}

Faculty members who participated with us in this critically self-reflective process described purposeful approaches to assessment in their courses. Their beliefs about quality learning and valuable learning outcomes had a more overt affect on their assessment practices than did institutional contexts. In addition, through the collaborative process of inquiry we used, we were able to identify several ways to improve educational development practices.

\section{Influences on teachers'assessment practices}

THE IMPACT OF TEACHERS' BELIEFS ON ASSESSMENT PRACTICES. Our participants were reflective instructors who cared about student learning, and 
their assessment practices supported their commitment to student learning. They expected their assessment activities to help students achieve the outcomes-that is, assessment was primarily for learning, not of learning.

Although their practices did fit their conceptions of teaching and beliefs about the purposes of assessment, it would be more accurate to say that teachers' practices reflected beliefs to the extent that their skills enabled them to do so. It was important to them to act in accordance with their beliefs, and they appeared to do so within the scope of their abilities. We sometimes suggested new assessment strategies that they had not yet tried, but if an idea did not support their beliefs they did not accept it.

Generally speaking, these faculty articulated sound rationales for their assessment approaches. Even the most tentative one said that he knew when something was "right" to do, even though he could not always explain why his choice was the right one. Like the other three, he looked to students for guidance-that is, he paid attention to student responses in considering the legitimacy and efficacy of an approach.

The fact that the teachers were mostly well aware of their intentions enabled them to be purposeful. In our experience as educational developers, many teachers are not so purposeful in their approach to assessment; rather, assessment is something they do because they have to. We observed that participants' intentionality was not a function of their specific underlying conceptions of teaching. Rather, it was the participants' level of awareness of their deeply held beliefs, values, and intentions that allowed them to be purposeful in their approach.

The college instructors' identity as disciplinary professionals with considerable prior experience in the workplace had a significant impact on their assessment practices. Although they taught full-time and described themselves as educators, they had a very strong connection to the workplace where they had once been and would be sending their graduates. This meant that they saw their role as preparing their students for work and viewed their previous work experience as a real asset in determining what to teach.

THE IMPACT OF INSTITUTIONAL CONTEXTS ON ASSESSMENT PRACTICES. We learned that institutional expectations and conditions influenced these teachers in a variety of ways, and the lens of teachers' conceptions mediated the impact of conditions on practice.

Class size proved to be a significant influence by restricting what was possible, although our participants responded differently to increasing class size. One of the university instructors, for example, stated adamantly that, no matter the size of her classes, she would always include extensive writing assignments because they enabled the kind of learning she valued, 
even though they increased her work load. The other university teacher commented that he had less confidence in his ability to grade effectively when he did not know his students, as was the case in very large classes. In his view, his assessment skills were the limiting factor. One college faculty member had changed from individual to group assignments to reduce the grading workload but realized that group work increased student learning. This teacher had also introduced multiple-choice questions but restricted them to testing factual knowledge. The other college teacher explained that her motivation for introducing rubrics was to save herself from writing extensive feedback to her many students, but she also learned that rubrics enhanced learning. Notably, none of the faculty claimed that small classes were necessary to ensure quality assessment.

Institutional policies about grading and assessment did have an impact on the teachers, though not in particularly significant ways. Mostly the faculty acted independently. They were responsible for most teaching and learning decisions and could choose to influence policies through their departments, if they wished. Most interesting to us was the teachers' blindness to how institutional policies might influence them, because they were so enmeshed in the environment. When instirutional contexts and personal beliefs conjoined, it was difficult to tease out the direction of the impact. Participants were likely to remark on those policies they did not agree with and would then explain how they managed to act in ways that reflected their own beliefs or how they might persuade colleagues to change the policy.

Institutional contexts did seem related to the participants' conceptions of teaching. The two college instructors leaned toward student- and learning-centered conceptions, while the two university teachers leaned toward a teacher and content focus. Both college instructors noted how important it was that students develop and demonstrate skills that make them successful in the workplace, whereas the university teachers expressed interest in assessing the quality of their students' critical thinking. One college teacher did show interest in developing her students' criticality, but her learning outcomes did not reflect that goal. Conversely, the university instructor who gave assignments to develop workplace skills felt like the "odd one out" in her department.

The climate for collegial interaction around teaching had a significant impact on the participants. The university faculty highlighted negative aspects of institutional climate, while the college faculty described a more supportive climate. The latter described regular opportunities to get together with departmental colleagues to discuss approaches to teaching and assessment. The university teachers described situations with no collegial interaction or with very uncomfortable, even antagonistic, interaction. 
They ventured outside their academic units to find colleagues with whom to discuss teaching and assessment.

At the outset of this project, we had wondered about the impact of preset learning outcomes on teaching. Might they affect a teacher's sense of ownership of the course and commitment to it? In fact, we learned that, because of their experience at the institution, the college instructors had shaped the learning outcomes in the courses they taught. Outcomes were not distributed from "on high" but were negotiated among the faculty who taught the course or related courses. The teachers explicitly tied their assessment practices to course learning outcomes and valued preset learning outcomes to guide their approaches to assessment.

\section{Working with Teachers to Understand and Improve Assessment Practices}

We hoped that this initiative would afford us the opportunity to encourage postsecondary faculty to adopt a critically self-reflective approach to assessment. In many ways, it did. Our asking teachers to give rationales for their assessment practices meant that critical self-reflection was inherent to their participation. We sometimes elicited quick responses indicating that reflection regularly permeated their practice. To other questions, notably those about collaborative approaches to criterion setting and the effects of negative language in rubric descriptors on learning, the response was, "That's an interesting question; I never thought to ask that before."

We identified some specific questions that were effective in inviting participants to explore their approach (see Exhibit 9.2) and found some general approaches that worked well in our interactions with these instructors (see Exhibit 9.3). The last two approaches of the five listed in Exhibit 9.3 recall Entwistle and Walker's study (2002), in which they guided university instructors to attend to previously ignored aspects of their practice. This shift in teachers' strategic alertness expanded their awareness of their practice and frequently led them to develop more sophisticated conceptions of teaching and learning. We found that our own attempts to guide teachers' attention in similar ways gave them the chance to view their practice through an alternative lens.

What didn't work? First, we found that paying too much attention to the assessment practices of their colleagues or the response of their colleagues to their own assessment practices seemed to provoke anxiety and discomfort and led some to justify their approach. Considering colleagues' approaches had only one positive outcome: helping the instructors articulate the uniqueness of their approach. Second, we found it challenging to use the 


\section{Exhibit 9.2. Effective Questions to Ask Teachers in Exploring Their Assessment Practices}

- Have you ever done/tried this ...?

Is there something you would like to try?

- What do you anticipate would be the result if you did this ...?

- How do you imagine your approach might change if ...

... There were no institutional requirements or policies?

... Class sizes were smaller (or larger)?

... You had no one to answer to?

- I noticed.... Did you notice that as well?

How did or do you make sense of that?

- Would you tell me more about ... (for example: the odd student, the difficult scenario, or the curious situation) that you mentioned earlier?

- My perception is that you do that ... for this reason. ... Am I correct?

\section{Exhibit 9.3. Effective Strategies for Interacting with Teachers Regarding Assessment Practices}

- Tie suggested or possible approaches to assessment to learning outcomes that are valued by the instructor-that is, explaining how a particular (alternative) approach might also support a specific goal the instructor has for students.

- Invite further reflection on how students have responded to their assessment practices, especially in terms of whether the students have achieved valued learning outcomes. Assume teachers are interested in furthering student learning.

- Acknowledge at the outset their successes as teachers.

- Introduce an alternative perspective by indicating, "In my experience ..." because most teachers value experience. Done sensitively, this approach honors all teachers' experiences but also invites teachers to reflect critically on their experience.

- Notice details and consider underlying intentions concerning the teachers' assessment practices. Assume that instructors had or have good reasons for the particular choices they make, but do not assume approaches are cast in stone.

side-shadow interview technique effectively in this context. Because many faculty already believe that it is professionally risky to give a third party access to their teaching tools, methods, strategies, and decisions, our participants seemed to interpret our "what if" and "why not" as challenging, almost adversarial. So we quickly decided to focus instead on such questions 
as, "What else have you tried and abandoned?" or "What other methods have you heard about and liked but haven't yet had a chance to try?"

We had also hoped that the project would help us improve our own practices as educational developers. Certainly the way we facilitated conversations with the participants fostered our own critical self-reflection. Rather than sticking to a set list of questions, we used any tactic that seemed reasonable to help the instructors to explain how they undertook assessment tasks and why they approached the tasks as they did. This, we think, was crucial. So much of educational development is normative and interventionist without sufficient attention paid to faculty's current understandings of teaching and their own practice. In this project, we engaged in in-depth conversation, openended dialogue that is not typical of many educational development interactions. Because we focused on helping ourselves better understand each teacher's approach, rather than helping the teacher better understand assessment, the instructors were quite willing to share and explain. Our questions tended toward those that requested further information, though we did not shy away from sharing our own experiences and ideas if we thought it would stimulate further reflection and a deeper response. This type of dialogue did indeed encourage reflection, and the issues raised by the teachers challenged us to really listen. In turn, our deep listening seemed to help the teachers address-and in some cases resolve-challenging assessment issues on their own. Inviting them to discuss artifacts from their assessment practice stimulated concrete, fruitful discussion about particular practices. In addition, our checking with participants about the validity of our assumptions as to the meaning of particular artifacts (or of particular questionnaire responses) was sometimes affirming (when we got it right) and at other times a well-deserved prompt to loosen our own tightly held views about what matters. Participants' stories of teaching included statements we did not readily agree with and thus challenged us to see the faculty in all their personal and professional complexity. In a traditional educational development context, we might actually feel compelled to voice our disagreement and perhaps become directive, but in this sharing-and-listening scenario, we felt no such compulsion. Perhaps this factor also increased the participants' openness. We heard the best stories after we'd spent some time and established trust with the teller.

\section{Conclusion}

Because we selected the four participants on the basis of their reputation as reflective and effective teachers, we were not surprised that they all focused on their students' learning when they designed and carried out 
assessment. They also responded to the particulars of their teaching situations, observant of class dynamics and fully prepared to adapt their practices to suit their students' learning needs. Their teaching beliefs had more of an impact on their assessment practices than did institutional context. However, the insidious pervasiveness of institutional context seemed to blind instructors to ways in which it might shape beliefs and practices.

Our conversations highlighted the complex relationship between teachers' beliefs about teaching and their experiences of teaching. Teachers' beliefs are immediately affected by their experiences in the classroom with particular students, which in turn are shaped by their beliefs. Conceptions of teaching, which guide practice, arise through the backand-forth interplay of experience and beliefs. For example, a beginning teacher who believed in the importance of feedback gave her student lots of it. When a student remarked on how helpful that feedback was to his learning, the instructor vowed to make time to offer all her students extensive feedback on their work. Her experience would have been very different if her first few students had never remarked on the feedback she gave them. Clearly, in working with teachers we need to address both their teaching experiences and their teaching beliefs, and tease apart the relationship between the two (Akerlind, 2003). In this way, conceptions can become more sophisticated, and faculty can learn to appreciate the practical implications of their conceptions.

Although our participants articulated rationales for how they conducted assessment, they reported being less successful in improving student learning by explaining their assessment strategies to their classes. We intend a follow-up project to investigate how closely tying assessment to learning outcomes using a formal framework, such as the ICE approach (Fostaty Young \& Wilson, 2000), may affect the faculty's teaching and their students' learning.

We found genuine value in working with successful teachers. Talking with those who excel at what they do put into words-teachers' words-what good practice is and made the tacit explicit. The participants told us they learned through this project, and three of them want to pursue their search for an assessment framework to share with students that would support their learning. We too learned a great deal. The project gave us valuable opportunities to examine our interactions with faculty and determine the practices and questions most successful in helping faculty understand, improve, and align their practice. Rather than intervening, we simply asked questions. We have modified our practice 
accordingly to respond to the real needs of instructors wanting to improve their assessment practices.

\section{REFERENCES}

Akerlind, G. S. (2003). Growing and developing as a university teacherVariation in meaning. Studies in Higher Education, 28(4), 375-390.

Akerlind, G. S. (2004). A new dimension to understanding universiry teaching. Teaching in Higher Education, 9(3), 363-375.

Biggs, J. B. (1999). What the student does: Teaching for enhanced learning. Higher Education Research and Development, 18(1), 57-75.

Biggs, J. B. (2003, April). Aligning teaching and assessing to course objectives. Paper presented at the International Conference on Teaching and Learning in Higher Education: New Trends and Innovations, University of Aveiro, Portugal.

Boud, D. (1990). Assessment and the promotion of academic values. Studies in Higher Education, 15(1), 101-111.

Brookfield, S. (1995). Becoming a critically reflective teacher. San Francisco: Jossey-Bass.

Entwistle, N., Skinner, D., Entwistle, D., \& Orr, S. (2000). Conceptions and beliefs about "good teaching": An integration of contrasting research. Higher Education Research and Development, 19(1), 5-25.

Entwistle, N., \& Walker, P. (2002). Strategic alertness and expanded awareness in sophisticated conceptions of teaching. In N. Hativa \& P. Goodyear (Eds.), Teacher thinking, beliefs, and knowledge in higher education (pp. 15-40). Dordrecht, Netherlands: Kluwer.

Fostaty Young, S., \& Wilson, R. (2000). Assessment and learning: The ICE approach. Winnipeg, Manitoba: Portage and Main Press.

Gass, L. (2004). McGraw-Hill lecture. Kingston, Ontario: Queen's University.

Gibbs, G., \& Simpson, C. (2003, Seprember). Measuring the response of students to assessment: The Assessment Experience Questionnaire. Paper presented at the International Improving Student Learning Symposium, Hinckley, UK.

Gibbs, G., \& Simpson, C. (n.d.). Does your assessment support your students' learning? Centre for Higher Education Practice, Open University. Retrieved November 30, 2008, from http://isis.ku.dk/kurser/blob .aspx? feltid $=157744$

Ho, A., Watkins, D., \& Kelly, M. (2001). The conceptual change approach to improving teaching and learning: An evaluation of a Hong Kong staff development programme. Higher Education, 42, 143-169.

Kane, R., Sandretto, S., \& Heath, C. (2002). Telling half the story: A critical review of research on the teaching beliefs and practices of university academics. Review of Educational Research, 72(2), 177-228. 
Kember, D. (1997). A reconceptualisation of the research into university academics' conceptions of teaching. Learning and Instruction, 7(3), 255-275.

Kember, D., \& Kwan, K. (2000). Lecturers' approaches to teaching and their relationship to conceptions of good teaching. Instructional Science, 28(5), $469-490$.

Louie, B. Y., Drevdahl, D. J., Purdy, J. M., \& Stackman, R. W. (2003). Advancing the scholarship of teaching through self-study. Journal of Higher Education, 74(2), 150-171.

Luce-Kapler, R. (2006). The side-shadow interview: Illuminating process. International Journal of Qualitative Methods, 5(1). Retrieved November 30, 2008, from www.ualberta.ca/iiqm/backissues/5_1/htm//uce-kapler.htm

Mezirow, J. (2000). Learning to think like an adult: Core concepts of transformation theory. In J. Mezirow \& Associates, Learning as transformation: Critical perspectives on a theory in progress (pp. 3-33). San Francisco: Jossey-Bass.

Pratt, D. D. (1992). Conceptions of teaching. Adult Education Quarterly, 42(4), 203-220.

Ramsden, P. (1992). Learning to teach in higher education. New York: Routledge.

Richards, J. C., \& Barksdale-Ladd, M. A. (1997, April). Creating and sharing teaching cases: A practical method of collaborative self-study. Paper presented at the 78th annual meeting of the American Educational Research Association, Chicago.

Samuelowicz, K., \& Bain, J. D. (1992). Conceptions of teaching held by academic teachers. Higher Education, 24(1), 93-111.

Samuelowicz, K., \& Bain, J. D. (2002). Identifying academics' orientations to assessment practice. Higher Education, 43(2), 173-201.

Schön, D. A. (1987). Educating the reflective practitioner. San Francisco: Jossey-Bass.

Whitehead, J. (1993). The growth of educational knowledge: Creating your own living educational theories. Bournemouth, UK: Hyde.

Wilcox, S. (2000). Promoting educational development: From models to modeling. Unpublished manuscript, Queen's University, Kingston, Ontario.

Wilcox, S., Watson, J., \& Paterson, M. (2004). Self-study in professional practice. In J. J. Loughran, M. L. Hamilton, V. K. L.aBoskey, \& T. Russell (Eds.), International handbook of self-study of teaching and teacher education practices (pp. 273-312). Dordrecht, Netherlands: Kluwer.

Wilson, R. J. (1990). Classroom processes in evaluating student achievement. Alberta Journal of Educational Research, 36(1), 4-17. 